\title{
Observing the Caldwell Objects
}

Springer

London

Berlin

Heidelberg

New York

Barcelona

Hong Kong

Milan

Paris

Singapore

Tokyo 
By the same author

The Art and Science of CCD Astronomy

ISBN 3-540-76103-9

Software and Data for Practical Astronomers:

The Best of the Internet

ISBN 1-85233-055-4 


\section{David Ratledge}

\section{Observing \\ the \\ Caldwell \\ Objects}

With 223 Illustrations 
Cover illustrations: Images by Christian Buil, Eric Thouvenot, Tim Puckett, Pedro Re, Steve Lee, Alex Richter and David Ratledge

ISBN 1-85233-628-5 Springer-Verlag London Berlin Heidelberg

British Library Cataloguing in Publication Data

Ratledge, David, 1945-

Observing the Caldwell objects

1.Astronomy-Observers' manuals 2.Astronomy-Charts, diagrams, etc.

I.Title

522.

ISBN 1852336285

Library of Congress Cataloging-in-Publication Data

Ratledge, David, 1945-

Observing the Caldwell objects / David Ratledge.

p. $\mathrm{cm}$.

ISBN 1-85233-628-5 (alk. paper)

1. Astronomy-Observers' manuals. 2. Astronomy-Charts,

diagrams. etc. 3. Galaxies-Charts, diagrams, etc. 4. Stars-ClustersCharts, diagrams, etc. 5. Nebulae-Charts, diagrams, etc. I. Title.

QB64.R37 2000

$523-\mathrm{dc} 21$

99-057027

Apart from any fair dealing for the purposes of research or private study, or criticism or review, as permitted under the Copyright, Designs and Patents Act 1988, this publication may only be reproduced, stored or transmitted, in any form or by any means, with the prior permission in writing of the publishers, or in the case of reprographic reproduction in accordance with the terms of licences issued by the Copyright Licensing Agency. Enquiries concerning reproduction outside those terms should be sent to the publishers.

๑) Springer-Verlag London Limited 2000

The use of registered names, trademarks etc. in this publication does not imply, even in the absence of a specific statement, that such names are exempt from the relevant laws and regulations and therefore free for general use.

The publisher makes no representation, express or implied, with regard to the accuracy of the information contained in this book and cannot accept any legal responsibility or liability for any errors or omissions that may be made. 


\section{Contents}

\section{Introduction}

How this book was compiled and Acknowledgements .. 1

\section{The 109 Caldwell Objects}

A Comprehensive Object-by-Object Guide

\section{Appendix A}

The Caldwell Objects and Visibility Limits

\section{Appendix B}

An Index to the Caldwell Objects

\section{Appendix C}

Observing Certificates

\section{All-Sky Caldwell Chart}

The location of every Caldwell Object .... Inside back cover 